\title{
Comparison of the influence of patch-scale and meadow-scale characteristics on flow within seagrass meadows: a flume study
}

\author{
A. Adhitya ${ }^{1,5, *}$, T. J. Bouma ${ }^{1}$, A. M. Folkard ${ }^{2}$, M. M. van Katwijk ${ }^{3}$, D. Callaghan ${ }^{4}$, \\ H. H. de Iongh ${ }^{5}$, P. M. J. Herman ${ }^{1}$

\begin{abstract}
${ }^{1}$ Royal Netherlands Institute for Sea Research (NIOZ), PO Box 140, 4400 AC Yerseke, the Netherlands
${ }^{2}$ Lancaster Environment Centre, University of Lancaster, Lancaster LA1 4YQ, UK

${ }^{3}$ Department of Environmental Science, Institute for Wetland and Water Research, Faculty of Science, Radboud University Nijmegen, PO Box 9010, 6500 GL Nijmegen, The Netherlands

${ }^{4}$ School of Civil Engineering, University of Queensland, Brisbane, Queensland 4072, Australia

${ }^{5}$ Institute of Environmental Sciences, CML/Conservation Biology, Van Steenis gebouw, Einsteinweg 2 ,
\end{abstract} \\ PO Box 22333 CC Leiden, The Netherlands
}

\begin{abstract}
Hydrodynamic processes are an important agent of stress and facilitation in seagrass meadows, but little is known about the effects of the common phenomenon of heterogeneity of seagrass meadows on their interactions with hydrodynamic processes. To address this gap in knowledge, 4 heterogeneous configurations of Posidionia oceanica mimics were analyzed in a laboratory flume. The 4 configurations were created by placing 4 boards of mimics, i.e. 2 with high shoot density $\left(\sim 1100\right.$ shoots $\left.\mathrm{m}^{-2}\right)$ and 2 with low shoot density $\left(\sim 400 \mathrm{~m}^{-2}\right)$, in different patterns (checkerboard, parallel, dense-sparse, and sparse-dense). Our results show that volumetric flow rate through each canopy, which is an indicator of the rate of supply of resources transported by the flow, tended to be greater in the low-density patches, regardless of the configuration. We also found that the Reynolds stress component $\tau_{\mathrm{Re}}$ was positive in the lower-density patches (indicating that horizontal momentum was being transferred into the patch) and negative in the high-density patches (indicating that horizontal momentum was being transferred upwards out of the patch). Our results suggest that in resource-limited environments, hydrodynamic processes favor the growth of lower-density patches in heterogeneous seagrass meadows, thereby causing meadows to become more homogeneous over time.
\end{abstract}

KEY WORDS: Seagrass · Posidionia oceanica · Hydrodynamics · Heterogeneity · Patches · Shoot density

Resale or republication not permitted without written consent of the publisher

\section{INTRODUCTION}

Seagrass meadows provide important ecosystem services in many coastal zone environments, such as sustaining biodiversity (Tanner 2003, Borg et al. 2005, Mills \& Berkenbusch 2009) and contributing to coastal protection (Pergent-Martini et al. 2006, Koch et al. 2009), carbon sequestration (Suzuki et al. 2003,
Apostolaki et al. 2011, Fourqurean et al. 2012), and nutrient accumulation (Gacia et al. 2002, Apostolaki et al. 2012). In part, these services are provided, either directly or indirectly, via the interaction of the meadows with the hydrodynamics of the ambient water. For example, seagrasses contribute to coastal protection directly by attenuating wave and tidal current energy (Nepf \& Vivoni 2000, Bouma et al. 2005, 
Koch et al. 2006). This also has the indirect effect of decreasing sediment erosion and increasing sediment deposition (Granata et al. 2001, Bos et al. 2007, Hendriks et al. 2008), which will reduce turbidity, enhance light availability, and thus enable further seagrass growth (van der Heide et al. 2007, Carr et al. 2010). The direct results of these interactions (which are purely physical), and their indirect consequences (which may be physical, chemical, ecological, or physiological), depend on 3 things: the nature of the incident flow, the substrate topography, and the physical characteristics of the seagrass meadow. Since little is known about the effects of the common phenomenon of heterogeneity of seagrass meadows on their interactions with hydrodynamic processes, our intention was to focus only on the last of these factors.

The relevant physical characteristics comprise the mechanical and morphological properties of seagrass meadows (Bouma et al. 2005, Peralta et al. 2008) and shoot density (shoots per unit area of bed surface), all of which may be measured locally, but which are also likely to show variability over larger spatial scales. In this study, we focus on the effects of shoot density, which influences mean flow speed and turbulence distributions (Gambi et al. 1990, Velasco et al. 2003, Fonseca \& Koehl 2006, Bos \& van Katwijk 2007) and related parameters such as canopy throughflow and bed shear stress (Nepf \& Vivoni 2000, Luhar et al. 2008), which in turn are likely to have a wide range of indirect effects, such as altering nutrient uptake rates (Thomas et al. 2000, Morris et al. 2008), sediment dynamics (Marbà \& Duarte 2001, Hendriks et al. 2008), and seagrass growth (van der Heide et al. 2007, Carr et al. 2010).

Larger-scale spatial variability of seagrass meadow physical properties, which is the norm in natural settings (den Hartog 1972, Koch et al. 2006), has also been found to have a strong influence on hydrodynamics (Townsend \& Fonseca 1998, Gacia et al. 2002, Fonseca \& Koehl 2006, Maltese et al. 2007, Folkard 2011), which in turn is likely to affect, for example, the transport and fate of sediment, seeds, pollen, and dissolved nutrients (Koch et al. 2006). Spatial heterogeneity may also cause flow acceleration around seagrass patches, producing local erosion (Bouma et al. 2009, van der Heide et al. 2010), and can influence sediment deposition and resuspension rates (Gacia \& Duarte 2001, Bouma et al. 2007, Temmerman et al. 2007). However, most studies of flow-seagrass interactions have assumed meadows to be homogeneous, and our understanding of how heterogeneous seagrass distributions interact with hydrodynamics remains limited.
In this work, we focus on how hydrodynamics (e.g. volumetric flow rate through and over the canopy, turbulence, Reynolds stresses, and solute fluxes) within homogeneous patches of seagrass depend on both the nature of the patches themselves ('patchscale' characteristics) and the nature of variations in seagrass density in their immediate neighborhood ('meadow-scale' characteristics). Specifically, we tested the null hypothesis that spatial patterns in shoot density at the meadow scale are no more or less important than shoot density values at the patch scale, in determining hydrodynamics within and above the canopy. To assess the relative importance of patchand meadow-scale characteristics for the hydrodynamics, we compared 4 different spatial configurations of a set of 4 homogeneous patches of plant mimics (2 patches of a higher shoot density and 2 of a lower shoot density). These spatial configurations represent, in a schematic way, vegetation heterogeneity as it may occur in natural seagrass meadows. Ecological consequences of patch- versus meadowscale effects on hydrodynamic resource supply to seagrasses are discussed.

\section{MATERIALS AND METHODS}

The experiment was carried out in a race track flume at the Royal Netherlands Institute for Sea Research (NIOZ, Yerseke, the Netherlands), measuring $17.55 \mathrm{~m}$ long, $0.6 \mathrm{~m}$ wide, and holding water of depth $0.4 \mathrm{~m}$ (Fig. 1; further details in Bouma et al. 2005). The free-stream velocity was set at $100 \mathrm{~mm} \mathrm{~s}^{-1}$. This velocity was used to represent hydrodynamic conditions that apply to many seagrass meadows, although lower and higher velocities can occur (Fonseca \& Koehl 2006, Bradley \& Houser 2009). Comparing different velocities was not feasible within the scope of the present study. Before starting measurements, the flume was allowed to run for 7 to $10 \mathrm{~min}$ to develop stable flow conditions, following previous testing and experiments in this facility. For practical reasons, we used fresh water in this experiment. The small difference in density between fresh $(\rho=$ $\left.1000 \mathrm{~kg} \mathrm{~m}^{-3}\right)$ and seawater $\left(\rho=1030 \mathrm{~kg} \mathrm{~m}^{-3}\right)$ was not expected to give significantly different results. Where relevant for the calculations (e.g. of Reynolds stress), we used the density of fresh water.

In the test section of the flume, we arranged boards of Posidonia oceanica-like mimics, fabricated following Folkard (2005). Such mimics have been found by several authors to offer a suitable approach to studying the biophysical interactions between seagrasses 
A) Race-track flume

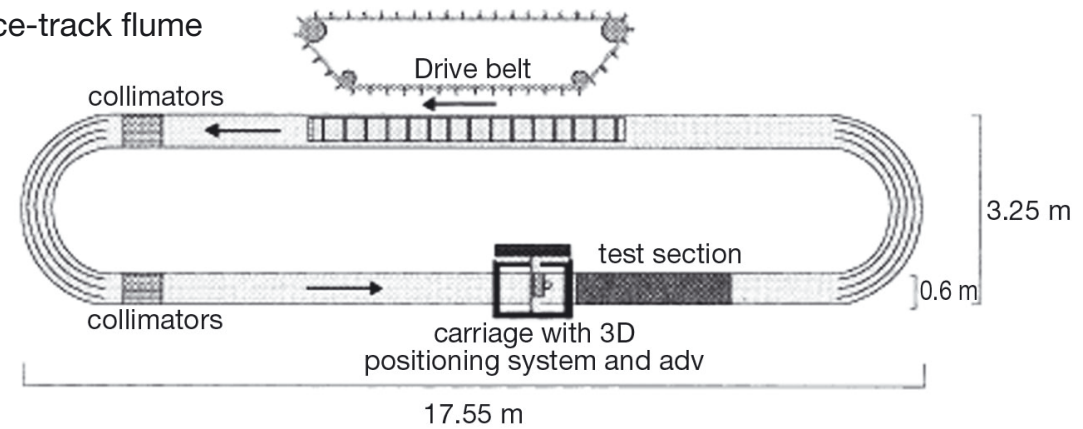

B) Seagrass patches setup

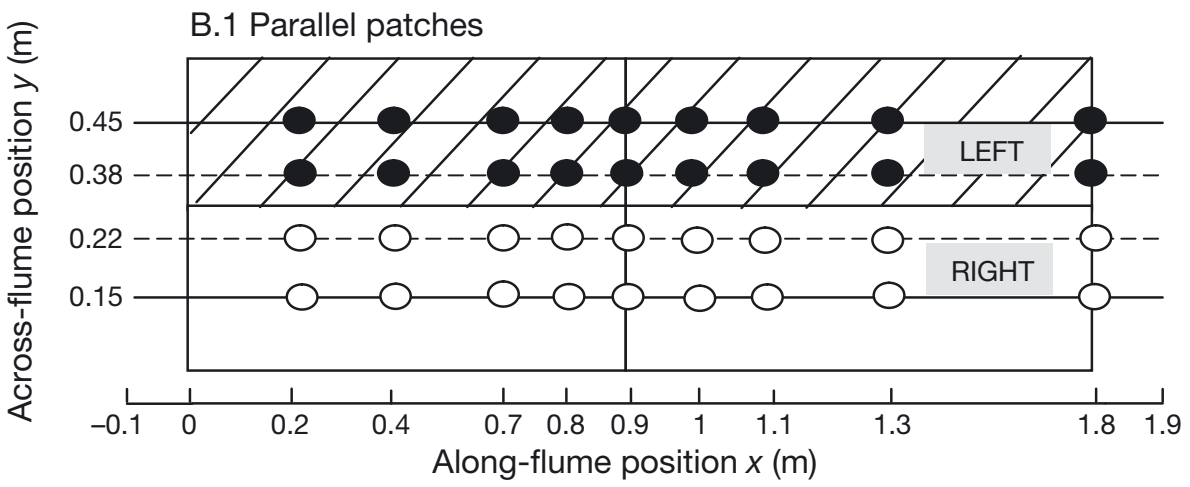

\section{B.2 Dense-sparse patches}

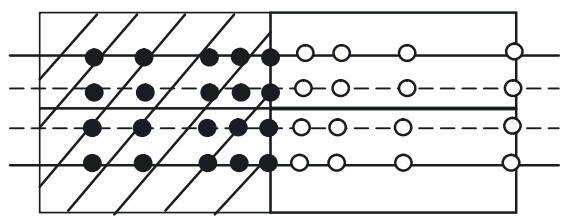

B.3 Sparse-dense patches

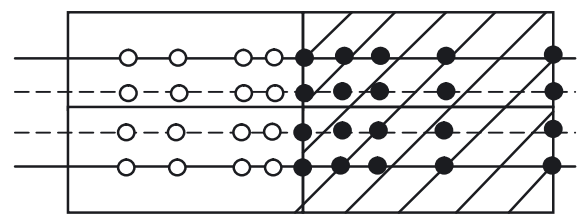

B.4 Checkerboard patches

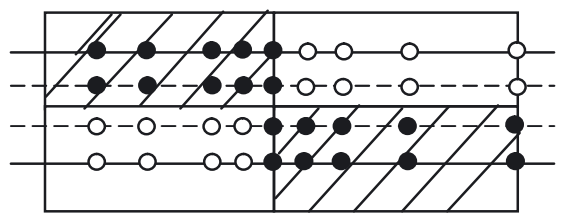

Fig. 1. Schematic diagram of (A) racetrack flume tank at the Netherlands Institute for Sea Research, Yerseke, and (B) top views of the 4 spatial configurations of seagrass mimic boards. The horizontal (vertical) axis indicates along-flume (across-flume) position; hatching (non-hatching) indicates high-density (low-density) patches. Locations of acoustic Doppler velocimeter (adv) profile measurements are shown as black circles for high-density patches and white circles for low-density patches

and hydrodynamics (e.g. Nepf \& Vivoni 2000, Frederiksen et al. 2004, Bouma et al. 2005, Peralta et al. 2008). Each mimic shoot had 3 leaf pairs with lengths of $0.5 \mathrm{~m}, 0.25 \mathrm{~m}$, and $0.15 \mathrm{~m}$, respectively. The mimic leaves were made of polyethylene sheeting (Decco) with thickness $\sim 2 \times 10^{-4} \mathrm{~m}$, density $\rho=9 \times 10^{-7} \pm 2 \times$ $10^{-8}( \pm \mathrm{SD}) \mathrm{kg} \mathrm{m}^{-3}$, modulus of elasticity $\mathrm{E}=(5.4 \pm 0.1)$ $\times 10^{8} \mathrm{~N} \mathrm{~m}^{-2}$, and coefficient of kinetic friction $\mu=0.47$ \pm 0.03 , all of which are comparable to average values of natural P. oceanica (Folkard 2005).

\section{Seagrass patch setup}

In each experimental run, we used 4 boards (each $0.9 \mathrm{~m}$ long and $0.3 \mathrm{~m}$ wide). Two were divided into
$0.03 \mathrm{~m} \times 0.03 \mathrm{~m}$ squares, to which we attached 1 mimic shoot per square to obtain a relatively high density (HD) of $\sim 1100$ shoots $\mathrm{m}^{-2}$. The other 2 boards were divided into $0.05 \mathrm{~m} \times 0.05 \mathrm{~m}$ squares, in which we again attached 1 mimic shoot per square to obtain a relatively low density (LD) of $\sim 400$ shoots $\mathrm{m}^{-2}$. Here we use the term 'density' to always refer to shoot density. In this experiment, the densities used are in the range of $P$. oceanica density values found in nature (Buia et al. 2004, Scardi et al. 2006). The 4 boards were arranged in the 4 possible different spatial configurations over the course of the experiment, which we refer to as parallel, checkerboard, densesparse, and sparse-dense (Fig. 1). Each pattern aimed to represent an element of natural seagrass heterogeneity. Thus, the checkerboard configuration simu- 
lated a fragmented pattern due, for example, to turtle grazing (Christianen et al. 2012) or the effect of a hydrodynamic energy gradient from high energy (producing patchy seagrass) to low energy (producing a continuous seagrass bed; Fonseca et al. 2002). Because of the idealized nature of the configurations, we completed a single experimental run for each configuration, following previous work of this type (e.g. see Newell \& Koch 2004, Folkard 2005).

\section{Flume measurements}

Vertical profiles of the flow velocity components in 3 orthogonal directions (along-flume, across-flume, and vertical, denoted $u, v$, and $w$, respectively) were measured at a set of horizontal locations inside and outside the patches for $30 \mathrm{~s}$ per point, at a frequency of $10 \mathrm{~Hz}$, using an Acoustic Doppler Velocimeter (Nortek field version). Reference velocity profiles over the bare flume bed were measured $0.1 \mathrm{~m}$ upstream of the patches (i.e. at $x=-0.1 \mathrm{~m}$, where $x$ is the alongflume coordinate and the leading edge of the patches is at $x=0$; Fig. 1). Velocity profiles within the patches were measured at $x=0.2,0.4,0.7,0.8,0.9,1,1.1,1.3$, and $1.8 \mathrm{~m}$. A final set of profiles was measured at $x=$ $1.9 \mathrm{~m}, 0.1 \mathrm{~m}$ downstream of the end of the seagrass. At each along-flume location, we measured profiles at 4 across-flume positions: $y=0.15,0.22,0.38$, and $0.45 \mathrm{~m}$ (where $y$ is the across-flume coordinate, measured from right to left when looking in the along-flume direction, and the right-hand wall of the flume is at $y=0$; Fig. 1).

Each vertical profile consisted of 12 measurement points, which were distributed as follows. For each run, we first measured the height of the top of the deflected canopy $\left(z_{\text {top }}\right)$ in each patch. We then took measurements at 6 locations around the top of the canopy, at $0.02,0.04$, and $0.06 \mathrm{~m}$ above and below $z_{\text {top. }}$. Three measurements were then made at locations evenly distributed between the top of the seagrass board $(z=0.05 \mathrm{~m})$ and $z_{\text {top }}-0.06 \mathrm{~m}$. Finally, 3 measurements were made at locations evenly distributed between the water surface $(z=0.31 \mathrm{~m})$ and $z_{\text {top }}+$ $0.06 \mathrm{~m}$. Here, $z$ is the vertical coordinate, and the base of seagrass board, which is level with the overall flume bed, is at $z=0$.

\section{Hydrodynamic parameters}

We measured or calculated hydrodynamic parameters as follows:
(1) Mean flow speed $\left(\mathrm{mm} \mathrm{s}^{-1}\right)$ in the along-flume $(\bar{U})$, across-flume $(\bar{V})$, and vertical $(\bar{W})$ directions, was measured at each point in each profile, to provide insight into how canopy spatial structure modifies current velocity and may create coherent flow patterns.

(2) Volumetric flow rate $\left(Q, \mathrm{~mm}^{3} \mathrm{~s}^{-1}\right)$ was calculated following Morris et al. (2008) as:

$$
Q=\sum_{i=1}^{n}\left(\frac{\overline{U_{i}}+\overline{U_{i-1}}}{2}\right)\left(z_{i}-z_{i-1}\right) w
$$

where $\bar{U}$ and $z$ are defined above, $\mathrm{w}(\mathrm{mm})$ is the width of each patch board, and the subscripts refer to the vertical positions at which each velocity measurement was taken. $Q$ was calculated for each of the 4 patches and the regions of clear water above them, giving 8 values for each configuration.

(3) The mean solute flux per unit leaf area $\left(N, \mathrm{~g} \mathrm{~s}^{-1}\right.$ $\mathrm{mm}^{-2}$ ) was calculated for each patch, assuming a uniform nutrient concentration in the incident flow, as:

$$
N=\frac{Q C}{A_{L}}
$$

where $C\left(\mathrm{~g} \mathrm{~mm}^{-3}\right)$ is the concentration of nutrients in the incident flow, and $A_{\mathrm{L}}\left(\mathrm{mm}^{2}\right)$ is the total leaf area within each patch. Because we used this parameter only in the form of ratios of its values between the LD and HD patches in each configuration, and the upstream nutrient concentration $C$ is assumed to be constant, the value of $C$ is not relevant (because it will always cancel out when ratios are calculated). Moreover, because constant shoot morphology is used throughout, the leaf area $A_{\mathrm{L}}$ can be substituted by the shoot density $(D)$. Hence, we can calculate the ratio of solute flux per unit leaf area between the $n$th LD patch and the $m$ th HD patch in each configuration as:

$$
\frac{N_{\mathrm{LD}-n}}{N_{\mathrm{HD}-m}}=\frac{Q_{\mathrm{LD}-n} D_{\mathrm{HD}-m}}{Q_{\mathrm{HD}-n} D_{\mathrm{LD}-m}}
$$

Since we have 2 LD patches (i.e. $n=1$ or 2 ) and 2 HD patches (i.e. $m=1$ or 2 ) in each configuration, we have 4 values of this solute flux ratio for each configuration $\left(N_{\mathrm{LD}-1}: N_{\mathrm{HD}-1} ; N_{\mathrm{LD}-1}: N_{\mathrm{HD}-2 ;} N_{\mathrm{LD}-2}: N_{\mathrm{HD}-1} ;\right.$ and $N_{\text {LD }-2}: N_{\text {HD-2 }}$.

(4) Turbulent kinetic energy (TKE, $\mathrm{mm}^{2} \mathrm{~s}^{-2}$ ) is one of the hydrodynamic parameters that governs processes such as the exchange of dissolved nutrients (Morris et al. 2008) and gases (Gambi et al. 1990) across leaf surfaces, and particle trapping and resuspension (Hendriks et al. 2008). This was calculated, at each point in each profile, from the root mean square turbulent velocity components, of which the along- 
flume component was calculated as $\overline{u^{\prime}}=\left(\overline{u^{\prime}(t)^{2}}\right)^{1 / 2}$ where $u^{\prime}(t)=u(t)-\bar{U}$ and $u(t)$ is the time series of quasi-instantaneous measurements of along-flume flow. The corresponding across-flume and vertical turbulent velocity components $\overline{V^{\prime}}$ and $\overline{W^{\prime}}$ were calculated in the same way, using the relevant mean and time series flow component values. TKE $\left(\mathrm{mm}^{2} \mathrm{~s}^{-2}\right)$ was then calculated as

$$
\mathrm{TKE}=\frac{1}{2}\left({\overline{u^{\prime}}}^{2}+{\overline{v^{\prime}}}^{2}+{\overline{W^{\prime}}}^{2}\right)
$$

(5) The Reynolds stress component $\tau_{\mathrm{Re}}=-\rho \overline{u^{\prime}(t) w^{\prime}(t)}$ $(\mathrm{Pa})$, where $\rho=1000 \mathrm{~kg} \mathrm{~m}^{-3}$ is the density of the water in the flume, was calculated at each point in each profile, in order to understand the distribution of vertical turbulent transfer within the patches. The sign of $\tau_{\operatorname{Re}}$ indicates the direction of momentum transfer: positive values indicate net downwards transfer of along-flume momentum, negative values indicate net upwards transfer of along-flume momentum.

\section{RESULTS}

\section{Canopy height}

The height of the seagrass patches depended strongly on both the patch-scale density and the meadow-scale configuration. In general, the HD patches had greater canopy heights, because the same incident force of the water flow on their frontal area was balanced by the resistive forces due to the rigidity of a greater number of leaves, meaning that the resistive force required per leaf was lower (Fonseca et al. 2008). However, the meadow-scale configuration (Table 1) strongly influenced the canopy heights to the extent that, for example, canopy heights of the LD patches in the dense-sparse configuration were higher than those of the HD patches in the sparse-dense configuration (Fig. 2).

\section{Volumetric flow rate through and over the canopy}

The spatial configuration of the seagrass patches had a major influence on the volumetric flow rate through each patch. In those runs where, at the leading edge, an LD patch was beside an HD patch (i.e. the parallel and checkerboard configurations), 55$56 \%$ and $42-43 \%$ of the flow travelled over the LD and HD patches, respectively (Table 1). In cases where there were 2 similar patches at the leading edge (i.e. the sparse-dense and dense-sparse configurations), between 45 and $48 \%$ of the flow traveled over the canopy, irrespective of the patch density (Table 1). These proportions persist at roughly the same level over the downstream half of each configuration (i.e. what starts above the canopy largely remains above the canopy, regardless of patch configuration). Only in the case of the checkerboard pattern do these percentages adjust in the downstream half of the configuration (Table 1). Note, however, that there is a mismatch in the measured total volumetric flow rate between the upstream and downstream pairs of patches of up to $7 \%\left(154 \mathrm{~mm}^{3} \mathrm{~s}^{-1}\right.$, in the sparse-dense configuration). This is evidently due to variations in flow speed in regions where we did not directly measure the flow speed.

The through-canopy volumetric flow rate is highest where there is a uniform LD canopy over the whole width of the section, and lowest in LD patches laterally paired with HD patches (Table 1). Here, the overflow predominantly follows the path of least resistance (the LD portion of the cross-section), resulting in a relatively strong flow which strongly pronates the LD canopy, reducing its volume and thus the volumetric flow rate through it (Fig. 2B,F) compared to all other leading edge patches.

\section{TKE and Reynolds stress}

In all of the configurations (Fig. 2), the maximum TKE values occurred near the top of the canopy, the

Table 1. Volumetric flow rate over and through canopies for the 4 meadow-scale configurations (parallel, sparse-dense, densesparse, and checkerboard), in $\mathrm{mm}^{3} \mathrm{~s}^{-1}$ with percentages of total volumetric flow rate in parentheses

\begin{tabular}{|c|c|c|c|c|c|c|c|c|}
\hline \multirow{3}{*}{$\begin{array}{l}\text { Patch mosaic } \\
\text { scale }\end{array}$} & \multicolumn{4}{|c|}{ Over } & \multicolumn{4}{|c|}{ Through } \\
\hline & $-\mathrm{L}$ & $\mathrm{ft} \longrightarrow$ & Ri & ht & -1 & - & 1 & $t$ \\
\hline & Front & Back & Front & Back & Front & Back & Front & Back \\
\hline Parallel & $870(42)$ & $835(41)$ & 1132 (55) & $1160(56)$ & $37(2)$ & $28(1)$ & $12(1)$ & $40(2)$ \\
\hline Sparse-dense & $996(45)$ & $955(47)$ & $1062(48)$ & $994(49)$ & $76(4)$ & $31(1)$ & $61(3)$ & $61(3)$ \\
\hline Dense-sparse & $985(48)$ & $946(48)$ & $978(48)$ & $905(45)$ & $42(2)$ & $65(3)$ & $32(2)$ & $79(4)$ \\
\hline Checkerboard & $900(43)$ & $925(46)$ & $1170(55)$ & $1027(51)$ & $20(1)$ & $33(2)$ & $11(1)$ & $9(1)$ \\
\hline
\end{tabular}




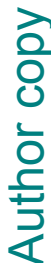
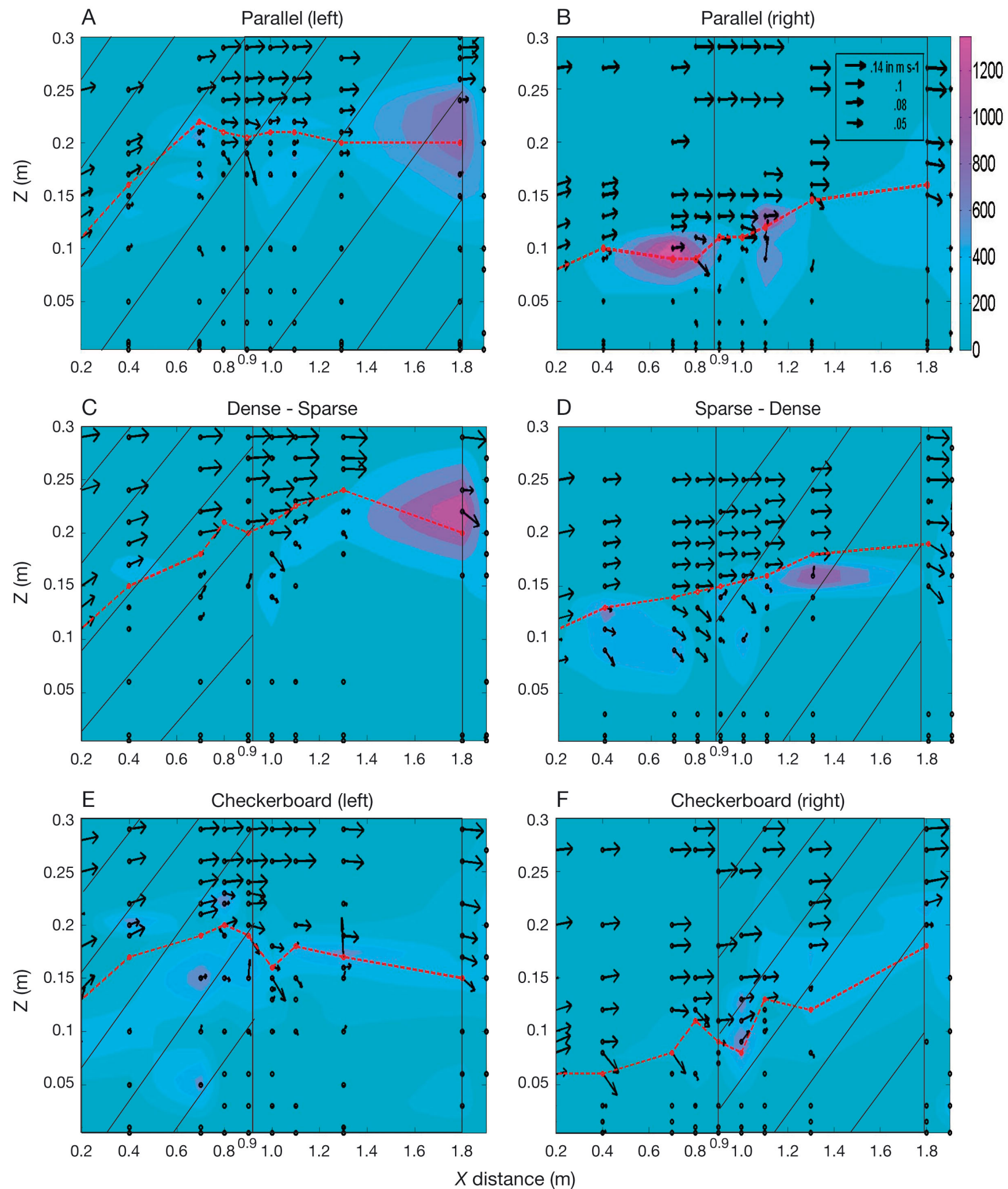

Fig. 2. Flow velocity (arrows, inset), canopy height (red dashed lines), and turbulent kinetic energy (colors, scale bar shows values in $\mathrm{mm}^{2} \mathrm{~s}^{-2}$ ) plotted in longitudinal section through the seagrass patches. Boxes with (without) oblique lines indicate high-density (low-density) patches. Plotted values have been averaged across the flume 
region of greatest velocity shear (between the slow in-canopy flow and the fast overflow). There is a general tendency for the TKE to increase downstream (as the velocity shear increases at the top of the canopy) and to be higher over the HD patches than over the LD patches, but these are not consistent patterns.

The Reynolds stress component $\tau_{\operatorname{Re}}$ has a rather patchy distribution (Fig. 3) but, like the TKE, is concentrated in the shear layer near the top of the canopy. There is a tendency for it to become positive towards the downstream end of the patches (Fig. 3A, $\mathrm{C}, \mathrm{E})$ as would be expected: as the shear at the top of the canopy increases, turbulence becomes stronger (Fig. 2) and will cause a net transfer of momentum downwards (positive $\tau_{\mathrm{Re}}$ ) from the rapid overflow into the canopy. In certain locations, mainly those where the height of the canopy is increasing downstream, $\tau_{\mathrm{Re}}$ is negative, indicating that the flow through the canopy at these points is faster than that immediately above it.

\section{Ratio of available solute flux per unit leaf area}

The mean values of the 4 solute flux ratios defined above were calculated for each configuration (Fig. 4). The dense-sparse configuration has a significantly higher value of this mean ratio than the parallel configuration, indicating that the LD patches in this configuration get significantly higher amounts of solute delivery per unit leaf area than in the parallel configuration. This is evidently because, in this case, the HD patches shelter the LD cases, allowing them to form a much less pronated canopy than in the parallel configuration, and thus receive a greater volumetric flow rate. The lower mean ratio in the parallel configuration evidently occurs because of the strong overflow and pronation seen in the LD patches in this case, which results in a lower volumetric flow rate through them. The checkerboard pattern has the highest variability, indicating that this configuration generates the greatest difference in solute flux values between the $2 \mathrm{LD}$ patches and between the $2 \mathrm{HD}$ patches.

\section{DISCUSSION}

The results presented here support the argument that, at least for the specific patch properties and meadow-scale patch arrangements studied in these experiments, spatial distribution of shoot density at the meadow scale is more important in determining hydrodynamic interactions within seagrass patches than the patch-scale shoot density. This can be seen in our measurements of volumetric flow rate apportionment (Table 1), flow speed (Fig. 2), TKE (Fig. 2), and Reynolds stress (Fig. 3).

Our findings hold true for cases with relatively low water depths, as used in our flume experiments. It should be noted that in cases with larger water depths, where the ratio of canopy height to water column height is less than 0.1, turbulence can more easily penetrate the canopy from the overlying water column (Nepf \& Vivoni 2000). Hence, in such situations, resource supply and hydraulic renewal within the canopy is determined by overlying TKE, as well as by the volumetric flow rate through the canopy (Nepf et al. 2007).

\section{Importance of patch scale vs. patch mosaic scale distribution}

In general terms, the results presented here confirm earlier observations of how higher shoot density (Gambi et al. 1990, Hendriks et al. 2008, Peralta et al. 2008) and spatial heterogeneity (Folkard 2011) inhibit flow intrusion and cause flow deflection around patches. Flow deflection from patches of higher shoot density to those of lower shoot density increases the availability of resources such as dissolved nutrients and gases to the latter (Nepf et. al 2007, Morris et. al. 2008). However, the present results also show that the pattern of canopy pronation within a heterogeneous seagrass meadow is complicated by its nonlinear relationship with the spatial distribution of the flow. Because of this, canopy height is not only determined by patch-scale shoot density but is also affected by the meadow-scale distribution of patches (e.g. compare the LD patches in Fig. 2B,D,E).

Understanding canopy pronation is important, as the volumetric flow rate over and through the canopy is a function of both the canopy height (and width) and the flow speed. At shoot densities typically found in natural seagrass meadows, volumetric flow rate through canopies is generally an order of magnitude slower than that over or around them (Gambi et al. 1990, Koch et al. 2006), a finding supported by our results (Table 1). Canopy height appeared to be the most important factor determining differences in throughcanopy volumetric flow rate, as the flow velocity within the vegetation was almost constant between treatments (Fig. 2), while, for example, the relatively high volumetric flow rate in the sparse-dense configuration is evidently due to the relatively high canopy 
응
은
은
근
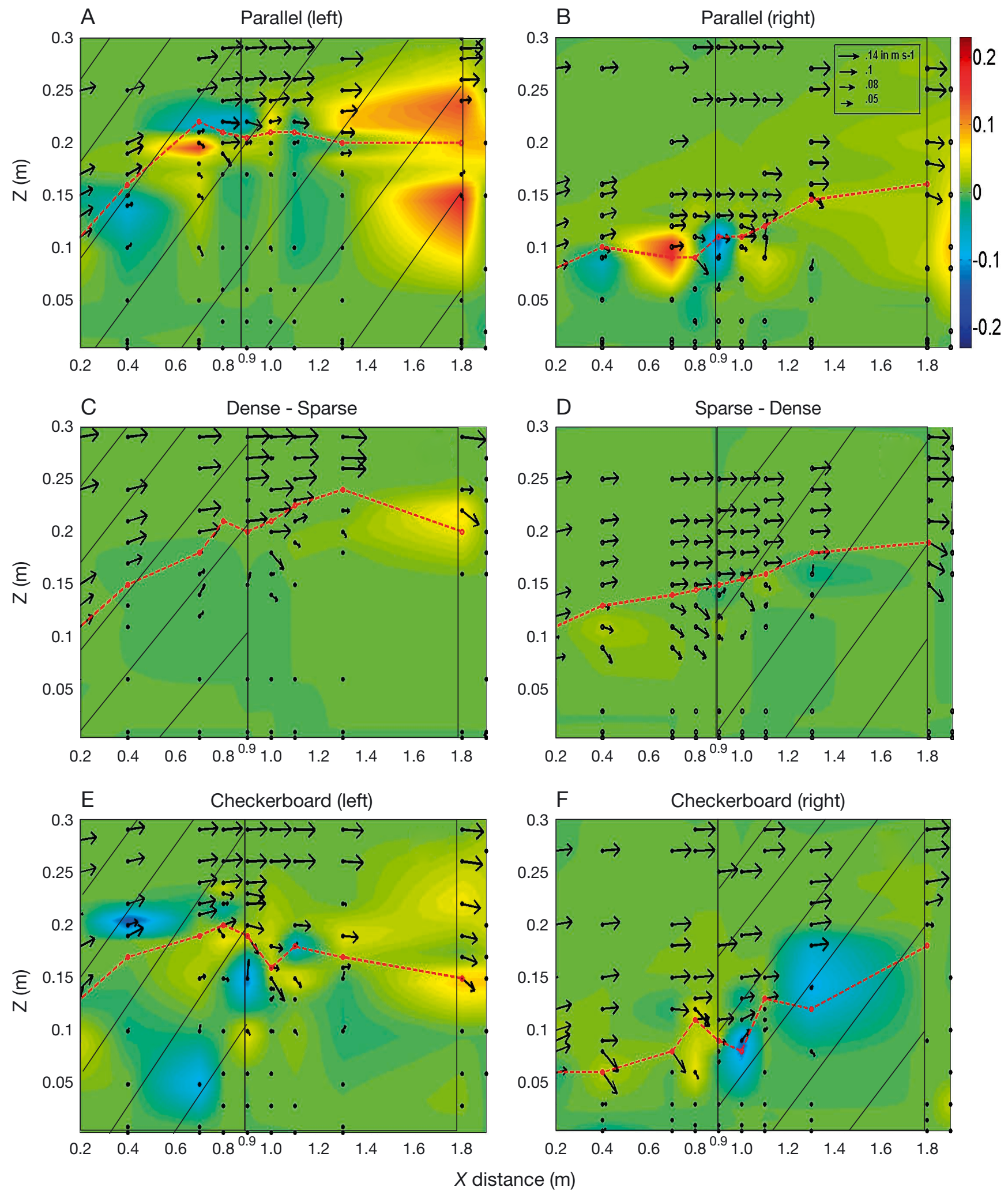

Fig. 3. Reynolds stress component $\tau_{\text {Re }}$ (contoured colors, scale bar shows values in Pascals), flow velocities (arrows, inset), and canopy height (red dashed lines) plotted along a longitudinal section through the seagrass patches. Boxes with (without) oblique lines indicate high-density (low-density) patches. Plotted values have been averaged across the flume 


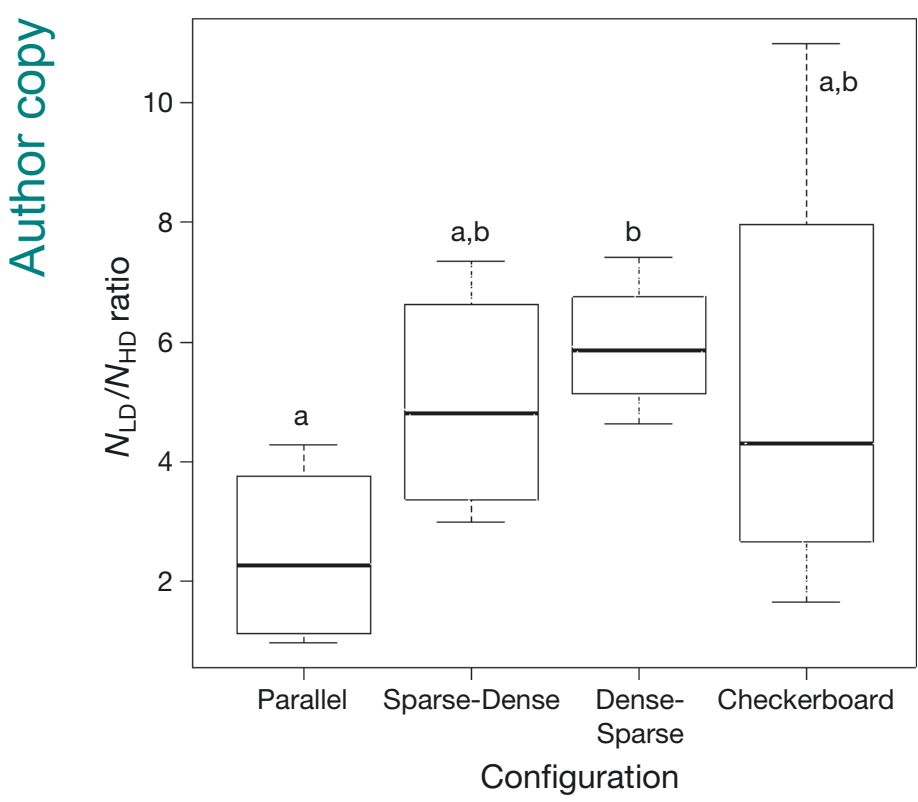

Fig. 4. Range of values of the ratio of solute flux $(N)$ per unit leaf area for low-density (LD) patches to that for high-density (HD) patches in each spatial configuration. Significant groupings are indicated by the letters a and b, as derived from pairwise Mann-Whitney tests (confidence threshold $\alpha=0.05$ ). Boxes represent 25th and 75th percentiles; median is shown, and whiskers are SD

in that case (Fig. 2). In contrast, differences in volumetric flow rates over the canopies appeared to be determined more by a combination of the amount of cross-sectional area above the canopy and the overflow speed, as both these factors vary between and within configurations (Fig. 2).

Comparing the different spatial patterns observed here reveals that parameters like canopy height and volumetric flow rate through and over the canopy are not only determined by local density but are also affected by the position of a patch within its local meadow-scale arrangement (e.g. compare the LD patches in Table 1). In general, most flow will be deflected over or around higher-density patches towards areas with less flow resistance, although some flow will always penetrate even the densest of patches. Understanding these flow-shoot density relationships is important for understanding the functioning of a seagrass meadow in terms of the uptake of limiting resources from the water column (Gambi et al. 1990, Folkard 2005, Morris et al. 2008).

It is also interesting to note a specific observation in the dense-sparse patch configuration case. The HD patches at the leading edge act as a barrier that shields the downstream LD patches. Nevertheless, the highest TKE values are observed at the downstream end of the LD patches rather than in the HD patches. This may be caused by the flow being forced over the HD patches, leading to a relatively rapid, 'skimming' overflow (Gambi et al. 1990, Koch et al. 2006), which builds up a strong shear layer between itself and the very weak throughflow also caused by the uniformly high-density seagrass in the upstream portion of the seagrass configuration.

\section{Ecological consequences of hydrodynamic interactions with meadow-scale heterogeneity in seagrass shoot density}

Heterogeneity in shoot density at the meadow scale, as schematized in our idealized experiment, may be regarded as an inherent characteristic of natural seagrass meadows (Koch et al. 2006). It may be caused by a wide variety of environmental factors, such as sedimentary processes, nutrient availability and patterns of colonization and disturbance (Balestri et al. 2003, Ruiz \& Romero 2003). Such meadow-scale heterogeneity in vegetation density is known to have important consequences for the functioning of both the seagrass and the communities it supports. For example, it can affect faunal abundance and species richness (Tanner 2003). It can also cause increased turbulence or flow acceleration, and thereby locally reduce the growth of organisms on seagrass leaves that, by their presence, hamper seagrass growth (Gambi et al. 1990). However, such increased turbulence or flow acceleration can also damage leaves and thereby cause a reduction in photosynthesis (Koch et al. 2006). These opposing effects demonstrate that interpreting the ecological consequences of altered hydrodynamics at a specific location is extremely complicated.

The importance of local (patch-scale) shoot density on hydrodynamic conditions within seagrass meadows has been well established (e.g. Peterson et al. 2004). The present work clearly demonstrates the importance of meadow-scale heterogeneity in vegetation density in addition to this. The delivery of resources to the seagrass and the organisms it supports is reliant on hydrodynamics. Our results indicate that in heterogeneous meadows, the solute flux rate per unit leaf area tends to be greater in lowerdensity patches than in higher-density patches. The implication of this is that lower-density patches would have greater access to hydrodynamically delivered, limiting resources (Gambi et al. 1990, Folkard 2005, Morris et al. 2008).

Assuming that hydrodynamic supply of resources affects growth rates, our results suggest that growing 
conditions are more favorable in lower-density patches than in neighboring high-density patches, because the lower-density patches have higher solute flux rates per unit leaf area. This would imply that the adjustment of hydrodynamic flows to meadow-scale heterogeneity is a factor that favors heterogeneous seagrass meadows becoming more homogeneous. Of course, a very wide range of other factors contributes to determining whether heterogeneous meadows become more or less homogeneous, such as nutrient cycling from sediment into the water column or vice versa, deposition or erosion, or animal grazing, and all of these would need to be taken into account in predicting their development.

Apart from meadow-scale heterogeneity within a single species, the present results are also relevant to meadows made up of species differing in vegetation density, e.g. Caulerpa racemosa and Posidonia oceanica or Spartina anglica and Zostera marina (Dumay et al. 2002, Peralta et al. 2008). As species interactions are typically highly complex, involving many processes, we refrain from speculating the ecological consequences of hydrodynamic effects following from meadow-scale heterogeneity caused by species mixtures, and only note that this is an interesting field for future studies.

Acknowledgements. We gratefully acknowledge KNAW, NWO, and WOTRO for funding this research (grant no. WT 84-644), and Monique de Jager and Liu Quan Xing from NIOZ, Yerseke, for their assistance in teaching Matlab for carrying out the data analysis.

\section{LITERATURE CITED}

Apostolaki ET, Holmer M, Marbà N, Karakassis I (2011) Reduced carbon sequestration in a Mediterranean seagrass (Posidonia oceanica) ecosystem impacted by fish farming. Aquacult Environ Interact 2:49-59

> Apostolaki ET, Vizzini S, Karakassis I (2012) Leaf vs. epiphyte nitrogen uptake in a nutrient enriched Mediterranean seagrass (Posidonia oceanica) meadow. Aquat Bot 96:58-62

Balestri E, Cinelli F, Lardicci C (2003) Spatial variation in Posidonia oceanica structural, morphological and dynamic features in a northwestern Mediterranean coastal area: a multi-scale analysis. Mar Ecol Prog Ser 250:51-60

> Borg JA, Attrill MJ, Rowden AA, Schembri PJ, Jones MB (2005) Architectural characteristics of two bed types of the seagrass Posidonia oceanica over different spatial scales. Estuar Coast Shelf Sci 62:667-678

> Bos AR, van Katwijk MM (2007) Planting density, hydrodynamic exposure and mussel beds affect survival of transplanted intertidal eelgrass. Mar Ecol Prog Ser 336: 121-129

Bos AR, Bouma TJ, de Kort GLJ, van Katwijk MM (2007) Ecosystem engineering by annual intertidal seagrass beds: sediment accretion and modification. Estuar Coast Shelf Sci 74:344-348

Bouma TJ, De Vries MB, Low E, Peralta G, Tanczos IC, van de Koppel J (2005) Trade-offs related to ecosystem engineering: a case study on stiffness of emerging macrophytes. Ecology 86:2187-2199

> Bouma TJ, van Duren LA, Temmerman S, Claverie T, Blanco-Garcia A, Ysebaert T, Herman PMJ (2007) Spatial flow and sedimentation patterns within patches of epibenthic structures: combining field, flume and modeling experiments. Cont Shelf Res 27:1020-1045

Bouma TJ, Friedrichs M, van Wesenbeeck BK, Temmerman S, Graf G, Herman PMJ (2009) Density-dependent linkage of scale-dependent feedbacks: a flume study on the intertidal macrophyte Spartina anglica. Oikos 118: 260-268

> Bradley K, Houser C (2009) Relative velocity of seagrass blades: implications for wave attenuation in low-energy environments. J Geophys Res 114, F01004, doi: 10.1029/ 2007JF000951

Buia MC, Gambi MC, Dappiano M (2004) Seagrass systems. Biol Mar Mediterr 11:133-183

Carr J, D'Odorico P, McGlathery K, Wiberg P (2010) Stability and bistability of seagrass ecosystems in shallow coastal lagoons: role of feedbacks with sediment resuspension and light attenuation. J Geophys Res 115: G03011

> Christianen MJA, Govers LL, Kiswara W, Roelofs JGM, Bouma TJ, Lamers LPM, van Katwijk MM (2012) Marine megaherbivore grazing may increase seagrass tolerance to high nutrient loads. J Ecol 100:546-560

Den Hartog C (1972) The sea-grasses of Brazil. Acta Bot Neerl 21:512-516

- Dumay O, Fernandez C, Pergent G (2002) Primary production and vegetative cycle in Posidonia oceanica when in competition with green algae Caulerpa taxifolia and Caulerpa racemosa. J Mar Biol Assoc UK 82:379-387

> Folkard AM (2005) Hydrodynamics of model Posidonia oceanica patches in shallow water. Limnol Oceanogr 50: 1592-1600

Folkard AM (2011) Flow regimes in gaps within stands of flexible vegetation: laboratory flume simulations. Environ Fluid Mech 11:289-306

Fonseca MS, Koehl MAR (2006) Flow in seagrass canopies: the influence of patch width. Estuar Coast Shelf Sci 67: $1-9$

- Fonseca MS, Whitfield PE, Kelly NM, Bell SS (2002) Modelling seagrass landscape pattern and associated ecological attributes. Ecol Appl 12:218-237

> Fonseca MS, Kenworthy WJ, Griffith E, Hall MO, Finkbeiner M, Bell SS (2008) Factors influencing landscape pattern of the seagrass Halophila decipiens in an oceanic setting. Estuar Coast Shelf Sci 76:163-174

Fourqurean JW, Duarte CM, Kennedy H (2012) Seagrass ecosystems as a globally significant carbon stock. Nat Geosci 5:505-509

Frederiksen M, Krause-Jensen D, Holmer M, Laursen JS (2004) Spatial and temporal variation in eelgrass (Zostera marina) landscapes: influence of physical setting. Aquat Bot 78:147-165

> Gacia E, Duarte CM (2001) Sediment retention by a Mediterranean Posidonia oceanica meadow: the balance between deposition and resuspension. Estuar Coast Shelf Sci 52:505-514

Gacia E, Duarte CM, Middelburg JJ (2002) Carbon and 
nutrient deposition in a Mediterranean seagrass (Posidonia oceanica) meadow. Limnol Oceanogr 47:23-32

Gambi MC, Nowell ARM, Jumars PA (1990) Flume observations on flow dynamics in Zostera marina (eelgrass) beds. Mar Ecol Prog Ser 61:159-169

Granata TC, Serra T, Colomer J, Casamitjana X, Duarte CM, Gacia E (2001) Flow and particle distributions in a nearshore seagrass meadow before and after a storm. Mar Ecol Prog Ser 218:95-106

Hendriks IE, Sintes T, Bouma TJ, Duarte CM (2008) Experimental assessment and modeling evaluation of the effects of the seagrass Posidonia oceanica on flow and particle trapping. Mar Ecol Prog Ser 356:163-173

Koch EW, Ackerman JD, Verduin J, van Keulen M (2006) Fluid dynamics in seagrass ecology - from molecules to ecosystems. In: Larkum AWD (ed) Seagrasses: biology, ecology and conservation. Springer, Dordrecht, p 193-225

Koch EW, Barbier EB, Silliman BR (2009) Non-linearity in ecosystem services: temporal and spatial variability in coastal protection. Front Ecol Environ 7:29-37

Maltese A, Cox E, Folkard AM, Ciraolo G, La Loggia G, Lombardo G (2007) Laboratory measurements of flow and turbulence in discontinuous distributions of ligulate seagrass. J Hydraul Eng 133:750-760

> Marbà N, Duarte CM (2001) Growth and sediment space occupation by seagrass Cymodocea nodosa roots. Mar Ecol Prog Ser 224:291-298

Mills VS, Berkenbusch K (2009) Seagrass (Zostera muelleri) patch size and spatial location influence infaunal macroinvertebrate assemblages. Estuar Coast Shelf Sci 81: 123-129

Morris EP, Peralta G, Brun FG, van Duren LA, Bouma TJ, Perez-Llorens JL (2008) Interaction between hydrodynamics and seagrass canopy structure: spatially explicit effects on ammonium uptake rates. Limnol Oceanogr 53: 1531-1539

> Nepf HM, Vivoni ER (2000) Flow structure in depth-limited vegetated flow. J Geophys Res 105:28547-28557

Nepf HM, Ghisalberti M, White B, Murphy E (2007) Retention time and dispersion associated with submerged aquatic canopies. Water Resour Res 43, W04422, doi:10.1029/ 2006WR005362

> Newell RIE, Koch EW (2004) Modeling seagrass density and distribution in response to changes in turbidity stemming from bivalve filtration and seagrass sediment stabilization. Estuaries 27:793-806

Peralta G, van Duren LA, Morris EP, Bouma TJ (2008) Con-

Editorial responsibility: Matthias Seaman,

Oldendorf/Luhe, Germany sequences of shoot density and stiffness for ecosystem engineering by benthic macrophytes in flow dominated areas: a hydrodynamic flume study. Mar Ecol Prog Ser 368:103-115

> Pergent-Martini C, Pasqualini V, Ferrat L, Pergent G (2006) Ecological data in integrated coastal zone management: case study of Posidonia oceanica meadows along the Corsican coastline (Mediterranean Sea). Environ Manag 38:889-895

> Peterson CH, Luettich RA Jr, Micheli F, Skilleter GA (2004) Attenuation of water flow inside seagrass canopies of differing structure. Mar Ecol Prog Ser 268:81-92

> Ruiz JM, Romero J (2003) Effects of disturbances caused by coastal constructions on spatial structure, growth dynamics and photosynthesis of the seagrass Posidonia oceanica. Mar Pollut Bull 46:1523-1533

> Scardi M, Chessa LA, Fresi E, Pais A, Serra S (2006) Optimizing interpolation of shoot density data from a Posidonia oceanica seagrass bed. Mar Ecol 27:339-349

> Suzuki Y, Fujii M, Casareto BE (2003) $\mathrm{CO}_{2}$ sequestration and fate of organic matters within seagrass (Zostera marina) ecosystem. J Chem Eng Jpn 36:417-427

> Tanner JE (2003) Patch shape and orientation influences on seagrass epifauna are mediated by dispersal abilities. Oikos 100:517-524

Temmerman S, Bouma TJ, Van de Koppel J, van der Wal DD, De Vries MB, Herman PMJ (2007) Vegetation causes channel erosion in a tidal landscape. Geology 35:631-634

Thomas FIM, Cornelisen CD, Zande JM (2000) Effects of water velocity and canopy morphology on ammonium uptake by seagrass communities. Ecology 81:2704-2713

Townsend EC, Fonseca MS (1998) Bioturbation as a potential mechanism influencing spatial heterogeneity of North Carolina seagrass beds. Mar Ecol Prog Ser 169: 123-132

- Van der Heide T, van Nes EH, Geerling GW, Smolders AJP, Bouma TJ, van Katwijk MM (2007) Positive feedbacks in seagrass ecosystems: implications for success in conservation and restoration. Ecosystems 10:1311-1322

- Van der Heide T, Bouma TJ, van Nes EH, van de Koppel J and others (2010) Spatial self-organized patterning in seagrasses along a depth gradient of an intertidal ecosystem. Ecology 91:362-369

Velasco D, Bateman A, Redondo JM, De Medina V (2003) An open channel flow experimental and theoretical study of resistance and turbulent characterization over flexible vegetated linings. Flow Turbul Combus 70:69-88

Submitted: December 19, 2012; Accepted: May 19, 2014 Proofs received from author(s): November 10, 2014 